Хиль Ирина Михайловна

кандидат юридических наук, доцент, доцент кафедры теории и истории государства и права Кубанского государственного университета

\section{РОЛЬ ИНТЕРИОРИЗАЦИИ В ПРОЦЕССЕ ФОРМИРОВАНИЯ ПРАВОВОГО СОЗНАНИЯ МОЛОДЕЖИ}

\section{Аннотация:}

В статье рассмотрены основные проблемы интериоризации - процесса освоения молодежью социального опыта в сфере восприятия и усвоения ими нравственных и правовых иенностей, морально-качественных ориентиров предшествующих поколений. Молодежь рассматривается как особая социально-демографическая группа с присущими только ей психофизиологическими характеристиками. Автором рассмотрены основные проблемы правовой социализации молодежи, особенности негативного отношения к восприятию опыта предшествующих поколений, обозначены социальные, экономические и иные факторы, влияющие на процесс формирования правового сознания молодежи. В работе предложены рекомендации и способы налаживания положительного восприятия молодым поколением традиций и норм общежития, семейного и гражданско-патриотического воспитания. Обозначены основные ориентиры для трансформации в сознании молодежи основных базовых правовых ценностей: справедливости, равенства, свободы и совести.

\section{Ключевые слова:}

интериоризация, правовое сознание, правовые ценности, нравственные ориентиры, гражданскопатриотическое воспитание, семья, молодежь, справедливость, равенство, свобода, совесть.
Khil Irina Mikhailovna

PhD in Law, Associate Professor, Theory and History of State and Law Department, Kuban State University

\section{THE ROLE OF INTERIORIZATION IN THE DEVELOPMENT OF THE LEGAL AWARENESS OF THE YOUTH}

\section{Summary}

The research describes the basic issues of interiorization, i.e. the development of youth social experience in the field of perception and understanding of moral and legal values, moral sense as a guideline of previous generations. Young people are considered as a particular social demographic group with their own psychophysiological characteristics. The author reviews the main problems of legal socialization of young people, the aspects of their negative attitude to the perception of the experience of previous generations. Social, economic and other factors influencing the development of the legal awareness of the youth are noted as well. The author provides recommendations for and ways of fostering positive views of the young generation on traditions and rules of coexistence, family, civic and national education. The guidelines for the transformation of the basic legal values (justice, equality, freedom, and conscience) in the minds of young people are defined.

Keywords:

interiorization, legal awareness, legal values, moral guidelines, civic and national education, family, youth, justice, equality, freedom, conscience.

Молодежному правосознанию свойственны неустойчивый характер, лабильность и отсутствие твердых жизненных позиций. Обладая психофизиологическими особенностями, молодежь воспринимает многое эмоционально, иначе воспринимает традиционные ценности и решает самостоятельно проблемы, но в силу отсутствия опыта последствий и результатов при достижении тех или иных целей обречены на неудачи. В.И. Чупров и Ю.А. Зубок отмечают, что «отличительное социальное качество молодежи... определяется способностью молодого поколения унаследовать и воспроизводить сложившуюся... структуру общественных отношений» [1].

Насколько серьезно мы отнесемся к воспитанию молодежи и передаче ей ценностей, насколько важен им будет жизненный опыт старших, настолько он может стать полезен не только для них, но и для их потомков, и в этом сегодня должно быть заинтересовано прежде всего старшее поколение. Жизненный опыт каждого нового поколения отличается от опыта других в силу изменения социальных условий, в которых этот опыт был приобретен.

Молодежь как особая социальная группа постоянно находится в фокусе исследований социологов, поскольку именно она является чутким индикатором происходящих перемен и определяет потенциал развития общества в целом. От того, насколько изучены мир ценностей современной молодежи, ее установки и жизненные планы, во многом зависит эффективность разрабатываемых мероприятий в области образования, в сфрере труда и занятости [2].

Современная молодежь может быть охарактеризована как многогранная социальная группа. Ей присущи как социально-политическая активность, так и политический пессимизм, потребительское отношение к жизни, безнравственность и в то же время заинтересованность в получении образования и в высоком саморазвитии. Однозначно одно: это та социальная группа, 
которой свойственны становление, формирование и восприятие опыта предыдущего поколения, привнесение нового в социальные отношения.

Интериоризация (франц. 'interiorisation' - переход извне внутрь, от лат. 'interior' - внутренний) - это, прежде всего применительно к теме исследования, усвоение внешней социальной деятельности, присвоение жизненного опыта. Следует отметить, что этот термин был впервые введен Л.С. Выготским. Суть интериоризации в данном случае - присвоение социального опыта через взаимодействие с носителем этого опыта.

Интериоризация, безусловно, может рассматриваться и как процесс развития и становления личности, и этот процесс, по мнению А.Г. Асмолова, трехгранен и включает в себя индивидуализацию, интимизацию и производство внутреннего плана сознания. Первая грань - это процесс совместной деятельности согласно основному генетическому закону культурного развития, вторая грань отражает переход от «мы» к «я», третья грань - это поэтапный переход действия во внутренний план. Необходимо отметить, что правовое сознание, на наш взгляд, также состоит из трех основных граней: правовой идеологии, правовой психологии и поведенческих элементов. Также следует подчеркнуть, что автор согласен с мнением Ю.К. Погребной, что правосознание является сложной социально-правовой категорией, играющей важную роль в механизме регуляции поведения личности в юридически значимых ситуациях. Так, посредством правосознания происходит теоретическое и практическое освоение правовой действительности, формируются навыки, установки и, в конечном счете, готовность к их использованию в реальных правовых отношениях [3]. Установлено, что структура правового сознания представляет собой единство трех диалектически взаимосвязанных уровней:

- обыденно-психологического, непосредственно отражающего правовые отношения людей в их повседневной жизнедеятельности;

- рационально-идеологического, связанного с исследованием круга явлений, познание которых необходимо для решения правовых проблем;

- ценностно-ориентационного, определяющего готовность личности к правомерному поведению [4].

Таким образом, если соотнести грани интериоризации и элементы правового сознания, то мы увидим, что правовая идеология как форма выражения правовых взглядов, принципов, требований общества вполне может отражать процесс и результат совместной деятельности основного генетического закона культурного развития, например, в правовом аспекте. При этом правовая психология как совокупность правовых чувств, ценностных отношений индивида вполне может быть соотнесена с гранью перехода от «мы» к «я», то есть от систематизированного научного выражения правовых взглядов общества к личностному отношению к праву в целом, основанному на восприятии «я» в этом праве. Наконец, переход действия во внутренний план действительно, по нашему мнению, может совпадать с таким структурным элементом правового сознания, как поведенческий (привычки, установки и готовность к деятельности). Таким образом, процесс интериоризации, а именно индивидуализация, интимизация и производство внутреннего плана сознания, на наш взгляд, может совпадать со структурной характеристикой правового сознания: правовой идеологией, правовой психологией и наличием поведенческих элементов.

Рассматривая интериоризацию как своеобразный связующий элемент для восприятия молодежью социально-ценностного фундамента современного общества, мы предлагаем проанализировать, что именно является средой для усвоения ценностей и формирования правового сознания молодежи. Формирование личностных качеств человека связано с освоением им определенной системы культуры, современного опыта, который не передается по наследству, а фрормируется путем особого механизма и факторов воздействия на формирование правового сознания и образцов социального поведения. Здесь важно подчеркнуть, что кризис правосознания свойственен любому времени - это как проблема взаимоотношений отцов и детей, которая всегда актуальна. Молодое поколение крайне неохотно воспринимает опыт «отцов», который во многом признается ими же - «отцами» - неудачным. Распад Советского Союза молодыми людьми во многом видится как несостоятельность и ошибочность политики всего предыдущего поколения, неправильность ценностей и целей всего общества. Как справедливо отмечает В.Н. Синюков, «надо ясно отдавать себе отчет в том, что после стольких катастроф отечественного права мы продолжаем сохранять черты правового общества практически исключительно благодаря глубинному правосознанию населения. Только оно, но никак, к сожалению, не государство, творчество законодателя дает результат в правовой культуре России. Только актуализация и рецепция этого правосознания... способны провести в будущем веке подлинную модернизацию отечественного права» [5]. Материальные, нравственные, культурные и всякие иные потребности личности всегда являются чисто историческими изменчивыми величинами. При одних условиях они могут способствовать развитию права, при других могут прямо препятствовать 
ему, при одних условиях благосостояние личности может зависеть от права, при других право может быть прямой помехой этому благосостоянию [6, с. 122]. Для молодежи сегодня свойственны инфантилизм, нигилизм, иждивенчество и прагматизм, одновременно ею отвергаются духовные и культурные ценности прошлого, формируются, а иногда и навязываются новые, асоциальные. Нестабильное сознание данной социальной группы легко подвержено манипуляциям и может стать объектом для удовлетворения не совсем правомерных интересов радикально настроенных групп и сообществ. В этом смысле молодежное сознание - как чистый лист, который никогда не будет пуст, его обязательно заполнят другие идеологии.

Сегодня молодежь воспитана не только и не столько на опыте старших - она впитала в себя все промахи и неудачи прошлых поколений и вовсе не для того, чтобы не совершать свои ошибки, a, скорее, чтобы было чем подтвердить неправильность этого жизненного опыта, его составляющих, тех морально-нравственных, семейных, социально-культурных норм, которыми жили их родители. Это обусловлено новыми условиями социального и экономического развития страны, условиями, в которых у старшего поколения отсутствует жизненный опыт, а у молодых другой сфреры жизни и не было, они родились при таких условиях. Немецкие социологи Х. Койпа и В. Хорштайн утверждают, что «в новых социально-экономических условиях наблюдаются медленные процессы внутренней модернизации, на руинах традиционных фрорм и образов жизни как эпидемия распространяется кризис различных видов социальной идентичности. Он не преодолевается продуктивно скачком из пассивности и безразличности к активности «я», а открывает внутренний мир человека для нарушений и болезнетворных вторжений» [7]. Правовое сознание молодого поколения с активной жизненной позицией без деформаций не может приобретаться генетически, и именно общество с его культурным наследием, традициями и нормами общежития передает его следующим поколениям для воспроизводства, усовершенствования и развития личности в целом. Современная молодежь, в отличие от старшего поколения, проходившего первичную социализацию в иных социально-экономических и политических условиях, фоормирует свои правовые ценности в принципиально иной обстановке, испытывая на себе все противоречия переходного периода развития российского общества. В то же время именно от молодежи зависит будущее страны, социализация новых поколений, призванных выйти из состояния социокультурного кризиса и сформировать институты гражданского общества. Возникшая ситуация предполагает проведение воспитательной работы, направленной на корректировку ценностных ориентаций, правового сознания молодежи и внедрение установок на соблюдение закона и правомерное поведение [8]. Фундаментальным в вопросах формирования правового сознания молодежи должны стать ориентиры на исторически сложившиеся нормы морали и общепризнанные нравственные ценности.

Без сомнения, формирование правосознания и позитивного поведения молодого гражданина во многом должно опираться на опыт старших поколений, механизм передачи этого опыта первоначально основывается на моральном климате в семье. Но на сегодняшний день родители скорее заинтересованы в материальном обеспечении детей, нежели в их гражданско-патриотическом воспитании, зачастую им некогда смотреть, чем заняты их дети, что они читают, о чем думают, чем живут. Семейное общение в век интернет-технологий стало искусственным, онлайн-общение между родителями и детьми встречается сегодня намного чаще, чем 20 лет назад. Хотя очень важно чтобы и сегодня существовала возможность формирования историко-патриотических представлений человека, складывающихся в феномен исторической памяти. Это формирование начинается с рассказов, сказок старших членов семьи о Родине, ее знаменитых людях, героях, народных умельцах [9]. Общение в семье восполняется и (или) полностью замещается интернет-общением в социальных сетях, пропагандой свободной любви, сексуальной распущенностью, выставлением напоказ всех граней сексуальных отношений, которые регулярно транслируются в программах передач многих телеканалов. И это тоже результат реакции на прошлое. Длительное время воспитание в стране строилось на запретах. Затем исчезли многие устойчивые понятия о жизненных ценностях [10], что сказывается теперь на воспитании молодого поколения.

Полное погружение в интернет-общение влечет за собой и другу проблему - интернет-аддикцию. Мы рассматриваем ее как зависимость в самом негативном смысле этого слова. Пока это заболевание описывается как недуг, требующий дальнейшего исследования, но ученые признают, что сегодня можно говорить о том, что интернет-зависимость - это СПИД и чума XXI в., а сетевым наркоманам нужны клиники и специальное лечение [11]. По мнению некоторых авторов, аддикция - это приспособление к сложным для индивида условиям деятельности и общения, то пространство, которое позволяет отдохнуть, порадоваться и опять вернуться (если получится) к реальной жизни [12, с. 64]. Ложность интернет-реальности в силу ее доступности, кажущейся свободе и безнаказанности поступков очень влечет подростков. У старшего поколения не было такой проблемы, а значит, оно не владеет эффективными способами ее решения. Жизнь в интернете может привести к потере связи с реальностью. Такие процессы приводят к сдвигу мотива 
деятельности с реальной цели на средства ее достижения, которые, в свою очередь, становятся новыми, суррогатными целями для субъекта [13]. Играя в ту или иную онлайн-игру, подростки примеряют на себя маски героев и им для этого не надо достигать поставленной жизнью цели становления культурно-развитой личности, а при проигрыше можно начать играть заново, сохранившись на определенном уровне, а значит, и ценность жизни уходит на второй план. На сегодняшний день имеется множество примеров агрессивного поведения подростков, которое имело зачастую смертельные последствия для одноклассников, учителей и самих детей, пытавшихся совершить самоубийство после актов агрессии в общественных местах, в учебных заведениях. На наш взгляд, бороться с негативным воздействием интернет-коммуникаций очень сложно, при этом правовая база регуляции этой сферы отношений заметно отстает от ее гиперразвития.

Анализируя тенденции социальных и правовых изменений формирования правового сознания молодого поколения [14], хотелось бы подчеркнуть, что сегодня очень остро стоит вопрос освоения молодежью социального опыта в сфере восприятия и усвоения ею нравственных и правовых ценностей, морально-качественных ориентиров предшествующих поколений. И этот вопрос как никогда актуален, потому что правосознанию молодежи присущи фррагментарность и прагматический характер интереса к праву, негативное восприятие практики его реализации, известный эклектизм и противоречивость воззрений, что подтверждается рядом социологический исследований [15].

Процесс трансформации правовых ценностей должен быть построен с учетом всех современных форм коммуникаций таким образом, чтобы молодежь была заинтересована в восприятии этого опыта. Политика общения государства с молодежью должна быть построена так, чтобы заинтересованность в самостоятельном изучении норм права была вызвана не столько требованием времени, сколько необходимостью этих знаний для успешного участия в жизни общества. Важно подчеркнуть, что источники правовой информации должны быть компетентными и качественными. Анализ субъективных факторов правовой культуры личности, качественное и ориентированное на положительный результат правовое просвещение в СМИ во многом могут способствовать коммуникативному общению между поколениями.

Именно первоисточники (информационно-правовые базы), литература по теории права, а не интернет-ресурсы должны стать фундаментом той правовой грамотности, которая позволит молодежи выстроить качественную структуру нравственных, культурных, моральных и правовых ценностей в целом. Позитивное восприятие права достигается путем совпадения положений закона с теми внутренними ценностями, которые восприняты с рождения: это справедливость, равенство, свобода и совесть, но молодые люди сегодня зачастую не понимают этих категорий и их ценностного содержания. Следует согласиться с Л.А. Тихомировым, что «свобода личности обеспечивается не столько какими-либо формами хорошо или плохо устроенного общества, а прежде всего потребностью личности в свободе, то есть развитостью личности» [16]. Развитие личности невозможно без познания нравственных ценностей и жизненных ориентиров предшествующих поколений. Как отмечает В.А. Мальцев, «право - не просто формальная система, социальный институт, а живой, пульсирующий организм, активный социальный фактор преобразования человеческого бытия, целесообразного изменения и стабилизации общественных отношений на основе исторически преемственных социокультурных программ. Право - это не сухая схематизированная теория, а практическое, опытное знание, повседневное и нормативное регулирование, активный и действенный регулятор социальных отношений» [17, с. 14]. Именно повседневная востребованность права, необходимость в нем позволяют постепенно формировать, реформировать и налаживать преемственную связь поколений через усвоение правил общежития, уклада морально-нравственных и социально значимых ценностей.

Общество развивается, расширяются границы понимания правовых ценностей в целом. Но самое главное - чтобы современное молодое поколение, провозглашая новые ценности миропонимания, осознавало ценность и суть таких слов, как «право», «свобода», «справедливость», «честь», «равенство», «совесть», сохраненные и переданные им предшествующими поколениями.

\section{Ссылки:}

1. Чупров В.И., Зубок Ю.А. Молодежь в общественном воспроизводстве: проблемы и перспективы. М., 2000.141 с.

2. Балкина Э.В. Тенденции социальных изменений современной молодежи [Электронный ресурс] // Студенческий научный форум-2015 : материалы VII Междунар. студ. электрон. науч. конф. URL: https://www.scienceforum.ru/2015/1210/12486 (дата обращения: 09.06.2018)

3. Погребная Ю.К. Правосознание современного российского общества (вопросы теории и методологии исследования) : автореф. дис. ... канд. юрид. наук. М., 2011. 27 с.

4. Науменкова К. В. Российское правосознание: специфика, структура, динамика : автореф. дис. ... канд. фрилос. наук. Красноярск, 2013. 23 с.

5. Синюков В.Н. Россия в XXI веке: пути правового развития // Журнал российского права. 2000. С. 9-17. 
6. Алексеев Н.Н. Основы философиии права. СПб., 1998. 256 с.

7. Койпа Х. Проблемы молодежи и пути их разрешения // ИНИОН : реферативный журнал. Сер. «Социология». 1993. № 1. С. 54. Цит. по: Савченко И.П. Молодежная политика как социальное управление : дис. ... д-ра социол. наук. Ростов н/Д., 2002. 302 с.

8. Буланова И.А. Трансформация правовых ценностей российской студенческой молодежи в контексте глобализации : автореф. дис. ... канд. социол. наук. Ростов н/Д., 2006. 23 с.

9. Захарова Е.М. Формирование гражданственности молодежи России // Молодежь: тенденции социальных изменений : сб. ст. / под ред. В.Т. Лисовского. СПб., 2000. С. 139.

10. Лисовский В.Т. Любовь, сексуальность, брак и семья как объекты социологического исследования // Молодежь: тенденции социальных изменений : сб. ст. / под ред. В.Т. Лисовского. СПб., 2000. С.221.

11. Жизнь в сети: первые признаки интернет-зависимости [Электронный ресурс] // Аргументы и факты. 2014. 4 февр. URL: http://www.aif.ru/health/psychologic/1096601 (дата обращения 09.06.2018).

12. Усова Е.Б. Психология девиантного поведения : учеб.- метод. комплекс. Минск, 2010. 180 с.

13. Холодов А.Ю. Психологические и психофизиологические особенности формирования игровой зависимости у современной молодежи // Научный форум: Педагогика и психология : сб. ст. по материалам II междунар. науч.-практ. конф. М., 2016. № 2 (2). С. 113-118.

14. Окольская Л.А. Желаемые качества детей в 1990-е и нулевые: родительский выбор между ценностями послушания и самостоятельности // Россия реформирующаяся : ежегодник. Вып. 15. М., 2017. С. 479-515 ; Савруцкая Е.П., Устинкин С.В. Динамика ориентаций молодежи в ее отношении к политическим институтам // Россия реформирующаяся : ежегодник. Вып. 15. М., 2017. С. 325-340 ; Их же. Анализ динамики качественных характеристик ценностного сознания молодежи России // Власть. 2011. № 10. С. 92-96 ; Трофимова И. Н. Гражданская социализация молодежи в современной России: ценности и практики // Гражданская социализация молодежи в современной России: ценности и практики // Профилактика проявлений экстремизма и терроризма как фактор обеспечения социальной безопасности в современной России : материалы Всерос. науч.-практ. конф. (Москва, 19 апреля 2017 г.) / под общ. ред. Р.Ф. Идрисова, Т.В. Волосовец, А.П. Андреева, Р.А. Андриановой, А.П. Вихряна. М., 2017. С. 160-171; Ценностные ориентации молодежи в ее отношении к системе политических институтов современной России / Е.П. Савруцкая, С.В. Устинкин, Т.И. Бикметова, А.В. Никитин // Власть. 2017. № 5. С. 7-17 ; Чередниченко Г.А., Шубкин В.Н. Молодежь вступает в жизнь (социологические исследования проблем выбора профессии и трудоустройства). М., 1985. 240 с.

15. Молодежь: тенденции социальных изменений : сб. ст. / под ред. В.Т. Лисовского. СПб., 2000.

16. Тихомиров Л.А. К вопросу о свободе 1893 [Электронный ресурс] // Русское самодержавие. Прошлое и будущее монархии в России. URL: http://samoderjavie.ru/node/555 (дата обращения 09.06.2018).

17. Мальцев В.А. Право как нормативно-деятельностная система // Правоведение. 2003. № 2 (247). С. 14-27.

\section{References:}

Alekseev, NN 1998, Fundamentals of philosophy of law, St. Petersburg, 256 p., (in Russian).

Balkina, EV 2018, 'Trends in social changes in modern youth', Studencheskiy nauchnyy forum-2015: materialy VII Mezhdunar. stud. elektron. nauch. konf., viewed 09 June 2018, <https://www.scienceforum.ru/2015/1210/12486>, (in Russian).

Bulanova, IA 2006, Transformation of legal values of Russian student youth in the context of globalization, PhD thesis abstract, Rostov-on-Don, 23 p., (in Russian).

Cherednichenko, GA \& Shubkin, VN 1985, Young people starts their life (sociological studies of choosing a profession and finding a job), Moscow, 240 p., (in Russian).

Chuprov, VI \& Zubok, YuA 2000, Youth in social reproduction: problems and prospects, Moscow, 141 p., (in Russian).

Kholodov, AYu 2016, 'Psychological and psychophysiological features of the game dependence in the modern youth', Nauch-

nyy forum: Pedagogika i psikhologiya: sb. st. po materialam II mezhdunar. nauch.-prakt. konf., No. 2 (2), pp. 113-118, (in Russian). Koipa, Kh 1993, 'Problems of youth and ways of their solution', INION: referativnyy zhurnal. Ser. "Sotsiologiya", No. 1, p. 54, (in Russian).

Lisovsky, VT (ed.) 2000a, 'Love, Sexuality, Marriage and family as the subject matter of sociological research', Molodezh': tendentsii sotsial'nykh izmeneniy: sb. st., St. Petersburg, p. 221, (in Russian).

Lisovsky, VT (ed.) 2000b, Youth: the trends in social change, collection of articles, St. Petersburg, (in Russian).

Maltsev, VA 2003, 'Law as a regulating and activity-based system', Pravovedeniye, No. 2 (247), pp. 14-27, (in Russian).

Naumenkova, KV 2013, Russian legal conscience: specific nature, structure, dynamics, PhD thesis abstract, Krasnoyarsk, 23 p., (in Russian).

Okolskaya, LA 2017, 'Desired qualities of children in the 1990s and 2000s: the parental choice between the values of obedience and independence', Rossiya reformiruyushchayasya: yezhegodnik, Iss. 15, Moscow, pp. 479-515, (in Russian).

Pogrebnaya, YuK 2011, The legal consciousness of modern Russian society (issues of research theory and methods), PhD thesis abstract, Moscow, 27 p., (in Russian).

Savchenko, IP 2002, Youth policy as a social management, D.Phil. thesis, Rostov-on-Don, 302 p., (in Russian).

Savrutskaya, EP \& Ustinkin, SV 2011, 'The analysis of the dynamics of qualitative characteristics of the value consciousness of the Russian youth', Vlast', No. 10, pp. 92-96, (in Russian).

Savrutskaya, EP \& Ustinkin, SV 2017, 'Dynamics of youth's guidelines in relation to political institutions', Rossiya reformiruyushchayasya: yezhegodnik, Iss. 15, Moscow, pp. 325-340, (in Russian).

Savrutskaya, EP, Ustinkin, SV, Bikmetova, TI \& Nikitin, AV 2017, 'Core values of young people in their attitude to the system of political institutions of modern Russia', Vlast', No. 5, pp. 7-17, (in Russian).

Sinyukov, VN 2000, 'Russia in the 21st century: the ways of legal development', Zhurnal rossiyskogo prava, pp. 9-17, (in Russian).

Tikhomirov, LA 2018, 'Concerning freedom in 1893', Russkoye samoderzhaviye. Proshloye i budushcheye monarkhii v Rossii, viewed 09 June 2018, <http://samoderjavie.ru/node/555>, (in Russian).

Trofimova, IN, Idrisov, RF, Volosovets, TV, Andreev, AP, Andrianova, RA \& Vikhryan, AP (eds.) 2017, 'Civil socialization of the youth in the modern Russia: values and practices', Profilaktika proyavleniy ekstremizma i terrorizma kak faktor obespecheniya sotsial'noy bezopasnosti v sovremennoy Rossii: materialy Vseros. nauch.-prakt. konf. (Moskva, 19 aprelya 2017 g.), Moscow, pp. 160-171, (in Russian).

Usova, EB 2010, Psychology of deviant behavior, manual, Minsk, 180 p., (in Russian).

Zakharova, EM \& Lisovsky, VT (ed.) 2000, 'The development of citizenship in the Russian youth', Molodezh': tendentsii sotsial'nykh izmeneniy: sb. st., St. Petersburg, p. 139, (in Russian). 